\title{
Effect of Orientation and Applied Load on Abrasive Wear Property of Brass 60:40
}

\author{
Mohd Shadab Khan ${ }^{1}$, Zahir Hasan², Syed Mohd Farhan ${ }^{3}$ \\ ${ }^{1}$ Department of Mechanical Engineering, Integral University, Lucknow, India \\ ${ }^{2}$ Jahagirabad Institute of Technology, Jahangirabad, India \\ ${ }^{3}$ Sri Ram Swaroop Memorial Group of Professional College, Lucknow, India \\ Email: mdshadabkhan@yahoo.com, zahir_hasan@yahoo.com, syedfarhan93@gmail.com
}

Received November 18, 2013; revised December 23, 2013; accepted December 30, 2013

Copyright (c) 2014 Mohd Shadab Khan et al. This is an open access article distributed under the Creative Commons Attribution License, which permits unrestricted use, distribution, and reproduction in any medium, provided the original work is properly cited. In accordance of the Creative Commons Attribution License all Copyrights @ 2014 are reserved for SCIRP and the owner of the intellectual property Mohd Shadab Khan et al. All Copyright (C) 2014 are guarded by law and by SCIRP as a guardian.

\begin{abstract}
Wear is a continuous process in which material is degraded with every cycle. Scientists are busy in improving the wear resistance. Approximately $\mathbf{7 5 \%}$ failure in components or machine parts is due to wear. The present paper investigates experimentally the effect of orientation and normal load on alloy of copper and zinc, i.e. Brass, and calculates weight loss due to wear. To do so, a multi-orientational pin-on-disc apparatus was designed and fabricated. Experiments were carried out under normal load 05-20 N, speed 2000 rpm. Results show that the withincreasing load weight loss increases at all angular positions. The loss in weight is maximum at zero degree (horizontal position) and minimum at ninety degree (vertical position) for a particular load. Maximum wear occurs when the test specimen is held at $0^{\circ}$ angle and minimum wear occurs when the specimen is held at $90^{\circ}$ angle for given applied load. The circumferential distance travel is constant for all positions and for all loads but still mass loss varies.
\end{abstract}

\section{KEYWORDS}

Abrasive Wear; Brass; Grinding Disc; Mass Loss; Orientation

\section{Introduction}

Wear is a continuous process in which material is degraded at every cycle. Kloss et al. emphasized the various tools such as wear measuring equipments, mathematical modeling, tribo meters and simulations are used for measuring wear resistance and wear rate over many decades. It was observed by several authors [1-11] that the variation of friction and wear rate depends on interfacial conditions such as normal load, geometry, relative surface motion, sliding speed, surface roughness of the rubbing surfaces, type of material, system rigidity, temperature, stick slip, relative humidity, lubrication and vibration. Among these factors, sliding speed and normal load are the two major factors that play a significant role for the variation of friction and wear rate. As reviewed by Becker, et al. [12], the three important wear mechanisms mentioned over the years are: corrosion, abrasion, and adhesion. Researchers also suggest some parameters like hardness, fatigue or tensile strength producing effect in wear rate. Hardness does give any indication of the wear resistance of a material; however studies have demonstrated that the addition of certain alloying elements increases the wear resistance but not the hardness. Brass 60:40 is widely used in numerous engineering applications where friction requirement is meager such as locks, gears, bearings etc., including transport and construction where superior mechanical properties such as tensile strength and hardness are essentially required. Typical mechanical properties for Brass 60:40 are presented in Tables 1 and 2.

This paper is in series with "Effect of Orientation and Applied Load on Abrasive Wear Property of Alumunium Alloy-Al6061" [13]. The objective of this work is to design a new type of pin on disc setup which can check wear rate or loss of weight of the selected specimen at different orientation and at different loads. 


\section{Materials and Methods}

In order to carry out the experimental work the following procedure is adopted:

(1) Design of Setup; (2) Materials Selection; (3) Wear Behavior.

\subsection{Design of Setup}

In view of the objective a set-up was needed to be designed which can calculate wear rate at different angular positions $\left(0^{\circ}, 30^{\circ}, 45^{\circ}, 60^{\circ}, 90^{\circ}\right)$ of work piece. The designed setup is shown in the Figure 1.

The set up has following different parts (1) Controller (2) D.C. Motor (3) Flange Coupling (4) Bearing (5) Main Frame (6) Frame(Angular) (7) Acrylic Sheet (8) Grinding Wheel (9) Specimen (10) Screw Jack (11) Load Cell.

\subsection{Selection of Material}

For the present investigation Brass 60:40 type Brass alloy has been selected. Tables 1 and 2 show the Chemical Composition of the Brass 60:40 alloy.

\subsection{Specimen Preparation}

The specimen for wear studies was cut from the Brass alloy plate. The specimen cross section used was $1 \mathrm{~cm} \times$ $1 \mathrm{~cm}$ with a thickness of $4.5 \mathrm{~cm}$. The top and bottom specimen surfaces were made planer by polishing against

Table 1. Properties of brass 60:40.

\begin{tabular}{cccccc}
\hline Elements & $\mathrm{Cu}$ & $\mathrm{Zn}$ & $\mathrm{Fe}$ & Tensile Strength & Shear Modulus \\
\hline $\mathrm{Wt} \%$ & $60 \%$ & $39.65 \%$ & $0.35 \%$ & $370 \mathrm{MPa}$ & $37 \mathrm{GPa}$ \\
\hline
\end{tabular}

Table 2. Properties of brass 60:40.

\begin{tabular}{cccc}
\hline Melting Point & Density & \multicolumn{2}{c}{ Modulus of Elasticity (E) Poison’s Ratio } \\
\hline $885^{\circ} \mathrm{C}-900^{\circ} \mathrm{C}$ & $8.49 \mathrm{gm} / \mathrm{cm}^{3}$ & $97 \mathrm{GPa}$ & 0.31 \\
\hline
\end{tabular}

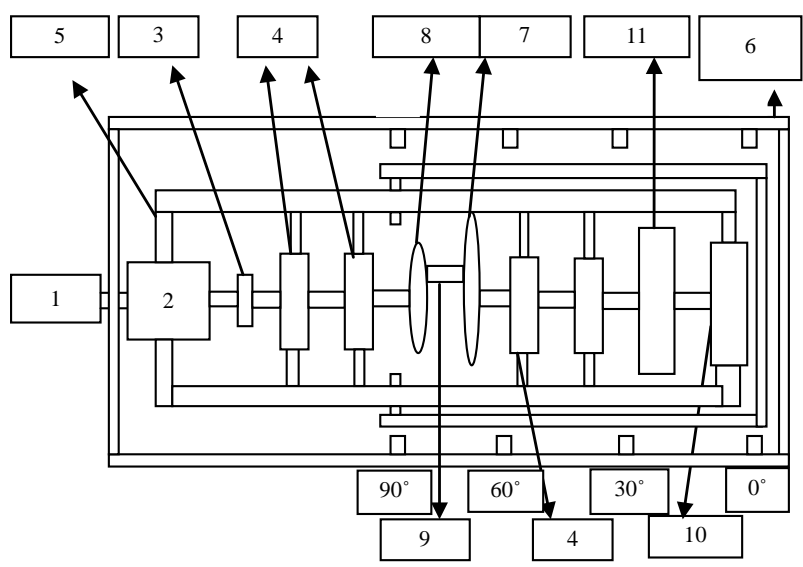

Figure 1. Design of setup. emery papers of appropriate grits. For the preparation of the surface to be used for wear studies, the final grit size of the emery paper was the same as the one to be used for the wear studies.

\subsection{Wear Characterization}

The following method was adopted for wear characterization.

\subsubsection{Selection of Applied Load and the Position of the Specimen \\ The following loads were selected for present objective}

(1) $5 \mathrm{~N}$ (2) $10 \mathrm{~N}$ (3) $15 \mathrm{~N}$ (4) $20 \mathrm{~N}$

For each load the position of the specimen was kept at $0^{\circ}, 30^{\circ}, 45^{\circ}, 60^{\circ}$ and $90^{\circ}$ respectively.

\subsubsection{Selection of Grinding Wheel}

The type of grinding wheel used for certain application, greatly influence the quality of the surface produced. Therefore, for different types of materials, different types of abrasive wheels can be used. Thus for Brass the grade of grinding disc taken is $\mathrm{C} 46-\mathrm{K} 6 \mathrm{~V}$.

\subsubsection{Speed of Grinding Wheel}

The speed of grinding disc is kept at constant value of $2000 \mathrm{rpm}$.

\subsubsection{Test Procedure}

Before the test the weight of the test specimen was taken accurately using an electronic balance with an accuracy of $0.001 \mathrm{~g}$. The maximum weighing capacity of the electronic balance was $320 \mathrm{~g}$. After a travel time of $05 \mathrm{mi}-$ nutes against the grinding disc, the sample was taken out carefully so that the debris's were removed from the valleys of the specimen and exact wear materials can be measured. Once again weight was taken carefully using the above balance and the difference in weight was noted. This was continued for five times with same specimen and at same position. After that next specimen was taken for next test condition i.e. $30^{\circ}$ angle and $5 \mathrm{~N}$ applied load and so on. The tests were conducted for five different orientations namely $0^{\circ}, 30^{\circ}, 45^{\circ}, 60^{\circ}$ and $90^{\circ}$. Thus a total of 25 reading is taken for one particular load. This is continued for load of $10 \mathrm{~N}, 15 \mathrm{~N}, 20 \mathrm{~N}$ respectively. The cumulative effect of weight loss was taken for calculating the wear mass.

\section{Results}

The effect of load on the specimen is shown in Figures 2-6 at various angular positions namely $0^{\circ}, 30^{\circ}, 45^{\circ}, 60^{\circ}$ and $90^{\circ}$ respectively. The mass loss of the materials is presented for loads $5 \mathrm{~N}, 10 \mathrm{~N}, 15 \mathrm{~N}, 20 \mathrm{~N}$. The effect of orientation on the specimen is shown in Figures 7-10. 
Grade of grinding disc taken is C46-K6V for Brass material.

\subsection{Effect of Load at Different Orientations}

- From Figure 2 it is observed that the wear mass increases from $0.916 \mathrm{gm}$ to $1.262 \mathrm{gm}$ as the applied load on the specimen increases from $5 \mathrm{~N}$ to $20 \mathrm{~N}$ when orientation of the specimen is $0^{\circ}$.

- From Figure 3 it is observed that the curve follows the same pattern as in graph 3.1. The wear mass increases from $0.908 \mathrm{gm}$ to $1.247 \mathrm{gm}$ as the applied load on the specimen increases from $5 \mathrm{~N}$ to $20 \mathrm{~N}$ when orientation of the specimen is $30^{\circ}$.

- From Figure 4 it is observed that the wear mass

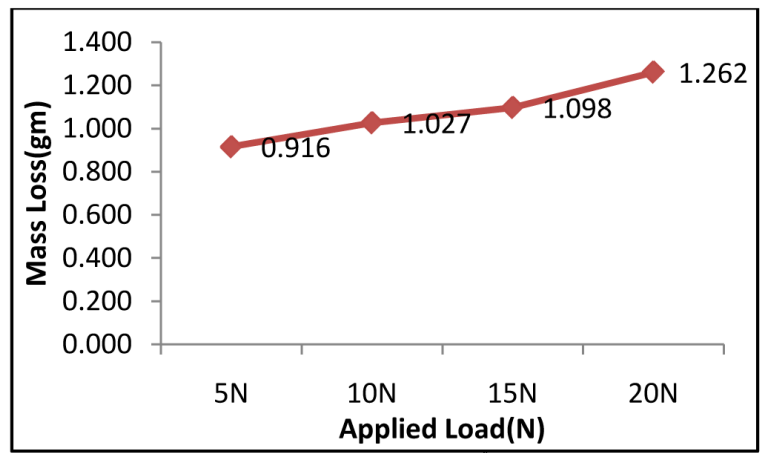

Figure 2. Effect of load at $0^{\circ}$ orientation.

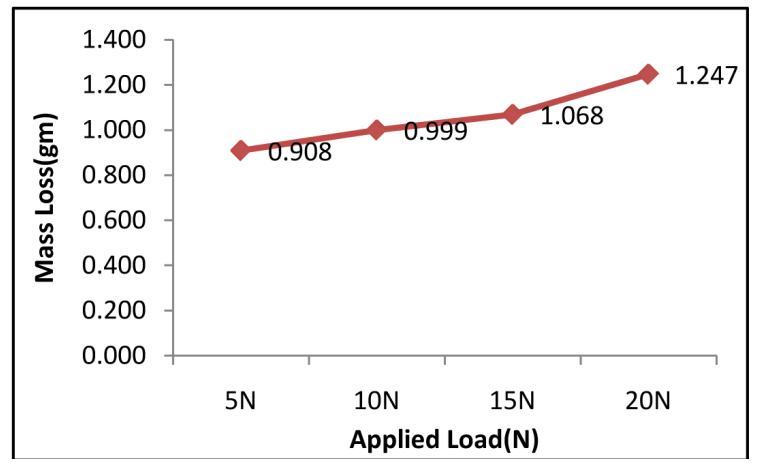

Figure 3. Effect of load at $30^{\circ}$ orientation.

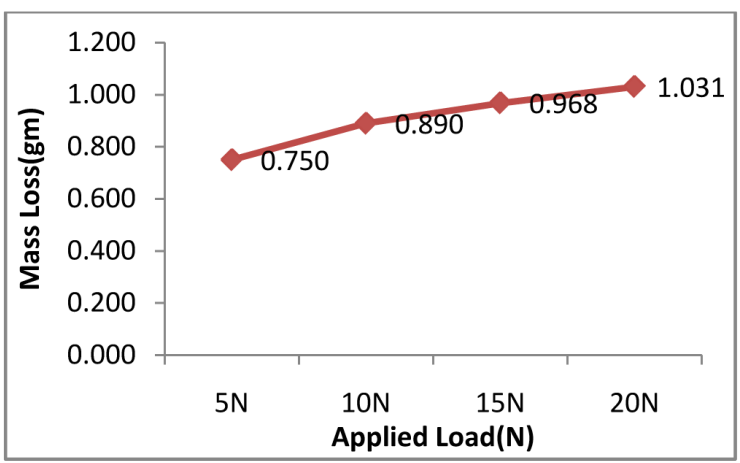

Figure 4. Effect of load at $45^{\circ}$ orientation. increases from $0.750 \mathrm{gm}$ to $1.031 \mathrm{gm}$ as the applied load on the specimen increases from $5 \mathrm{~N}$ to $20 \mathrm{~N}$ when orientation of the specimen is $45^{\circ}$.

- From Figure 5 it is observed that the wear mass increases from $0.589 \mathrm{gm}$ to $0.865 \mathrm{gm}$ as the applied load on the specimen increases from $5 \mathrm{~N}$ to $20 \mathrm{~N}$ when orientation of the specimen is $60^{\circ}$.

- From Figure 6 it is observed that the wear mass increases from $0.303 \mathrm{gm}$ to $0.638 \mathrm{gm}$ as the applied load on the specimen increases from $5 \mathrm{~N}$ to $20 \mathrm{~N}$ when orientation of the specimen is $90^{\circ}$ [11].

\subsection{Effect of Orientation at Different Load}

The following observations were made:

- From Figure 7 it is observed that as the orientation of the specimen changes from $0^{\circ}$ to $90^{\circ}$, the wear mass decreases from $0.916 \mathrm{gm}$ to $0.303 \mathrm{gm}$ when applied load is $5 \mathrm{~N}$.

- From Figure 8 it is observed that the wear mass follows the same pattern as in graph 3.6. The wear mass decreases from $0.1 .0274 \mathrm{gm}$ to $0.4048 \mathrm{gm}$ as the orientation changes from $0^{\circ}$ to $90^{\circ}$ when applied load is $10 \mathrm{~N}$.

- Similarly from Figures $\mathbf{9}$ and $\mathbf{1 0}$ it is observed that the wear mass decreases from $1.098 \mathrm{gm}$ to $0.512 \mathrm{gm}$ and from $1.261 \mathrm{gm}$ to $0.638 \mathrm{gm}$ respectively as the orientation of the specimen changes from $0^{\circ}$ to $90^{\circ}$ when applied loads are $15 \mathrm{~N}$ and $20 \mathrm{~N}$ respectively.

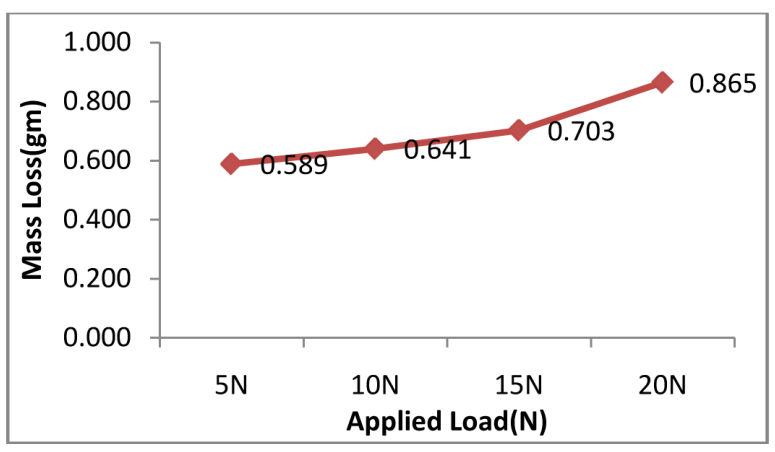

Figure 5. Effect of load at $60^{\circ}$ orientation.

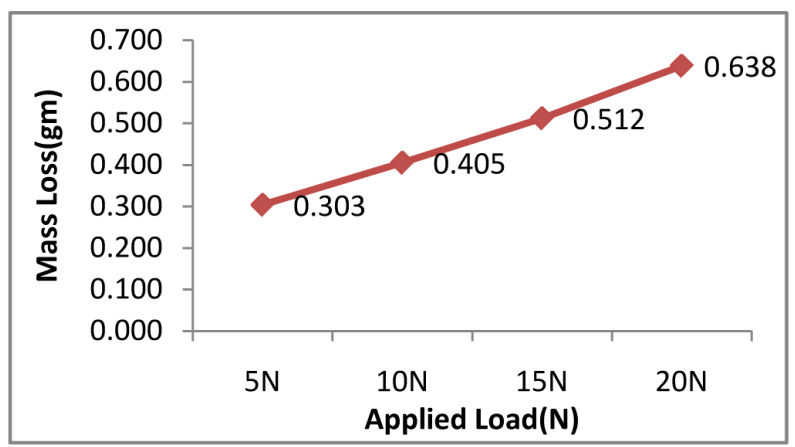

Figure 6. Effect of load at $90^{\circ}$ orientation. 


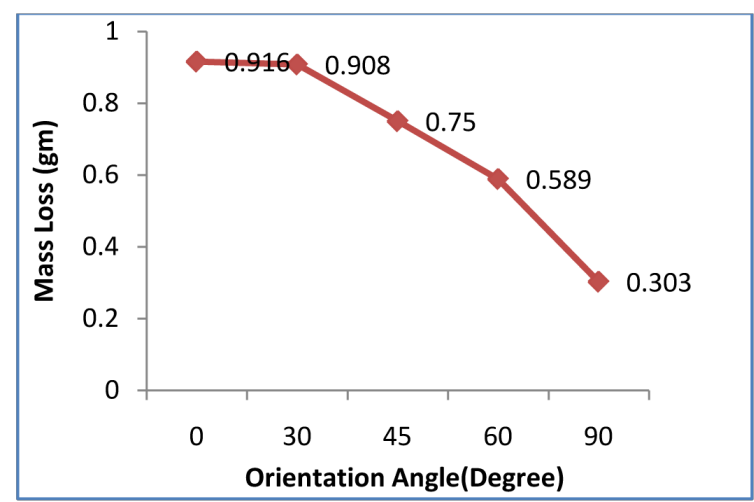

Figure 7. Effect of orientation angle at $5 \mathbf{~ N}$

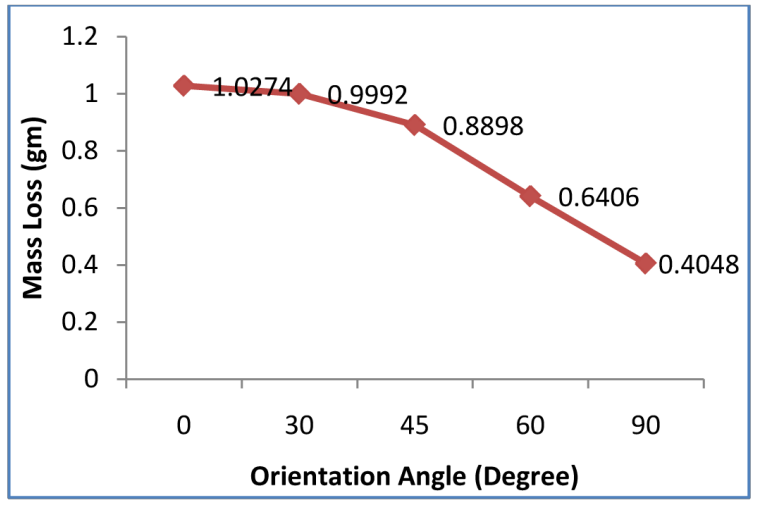

Figure 8. Effect of orientation angle at $10 \mathrm{~N}$.

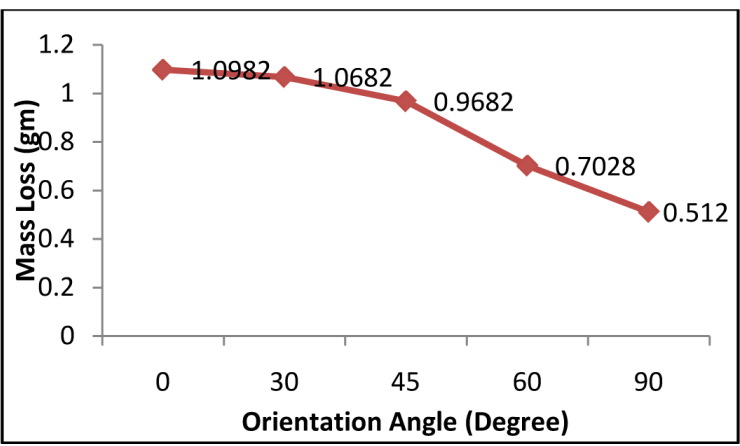

Figure 9. Effect of Orientation angle at $15 \mathbf{N}$.

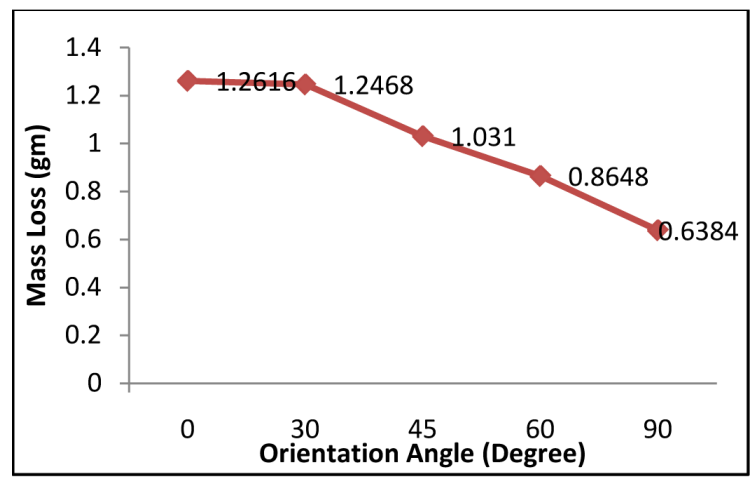

Figure 10. Effect of orientation angle at $20 \mathrm{~N}$.

\section{Discussion}

As the position changes from 0 degree to 90 degree, the forces applicable on the debri-particle changes, this changes the motion of debri-particle. Therefore a complete analysis of forces applicable done. The variation of wear mass shown in the above graph shows that as position changes from zero degree to 90 degree wear mass decreases due to the changes in orientation of forces. The Figure 11 shows orientation at 0 degree whereas Figure 12 shows orientation at 90 degree. It can be concluded that:

\subsection{At 0 Degree}

- It can be seen from the FBD in Figure 11 that weight of debri-particle (mg) and centrifugal force $\left(\mathrm{mrw}^{2}\right)$ add to each other. The debri do not trap in between specimen and abrasive disc. Due to addition of wt. of debri-particle and centrifugal force, the debri-particle of specimen falls.

- It becomes two body abrasions against general perception.

- The Brass alloy (Brass 60:40) gets fresh abrasive surface, due to this wear resistance decreases.

\subsection{At 90 Degree}

- It can be seen from the FBD in Figure 12 that the set-up rotates to 90 degree. The load on the specimen adds to weight of debri-particle and centrifugal force $\left(\mathrm{mrw}^{2}\right)$ and weight (mg) are perpendicular to each other.

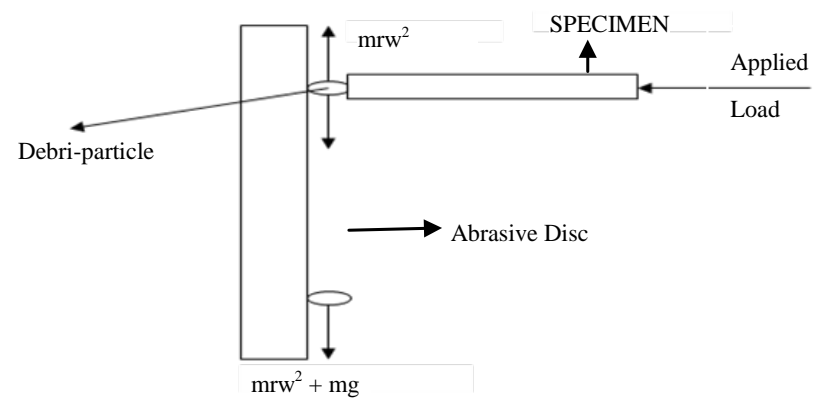

Figure 11. Specimen at $0^{\circ}$ (horizontal).

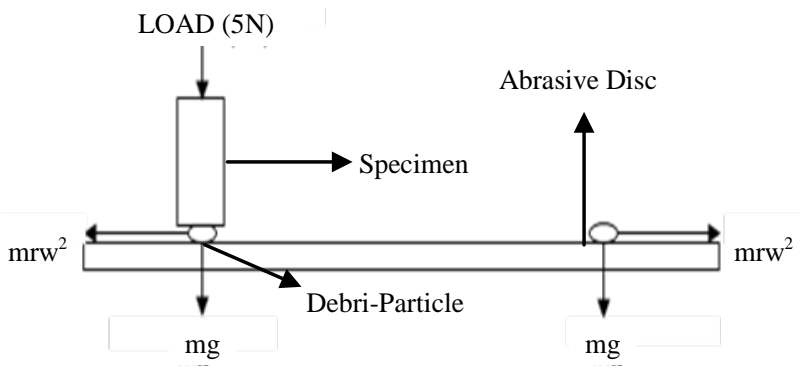

Figure 12. Specimen at $90^{\circ}$ (vertical). 
- Since debri traps in between specimen and abrasive disc hence it becomes three body abrasions due to this Brass 60:40 do not get fresh abrasive surface.

- This Change in nature of forces increases the wear resistance.

\section{Conclusions}

On the basis of experimental work, the following conclusions can be drawn:

1) With increasing load, wear (mass loss) increases at all angular positions, and this is in agreement with M. A. Chowdhury, M. K. Khalil, D. M. Nuruzzaman and M. L. Rahaman [11];

2) The loss in mass is maximum at zero degree (horizontal position) for a particular load;

3) The loss in mass is minimum at ninety degree (vertical position) for a particular load;

4) Maximum wear occurs when the test specimen is held at $0^{\circ}$ angle;

5) Minimum wear occurs when the specimen is held at $90^{\circ}$ angle for given applied load;

6) The circumferential distance travel is constant for all positions and for all loads, but weight loss still varies [14].

\section{REFERENCES}

[1] J. F. Archard, "Wear Theory and Mechanisms," In: M. B. Peterson and W. O. Winer, Eds., Wear Control Handbook, ASME, New York, 1980, pp. 35-80.

[2] D. Tabor, "Friction and Wear-Developments over the Last 50 Years, Keynote Address,” In: Proceedings of International Conference on Tribology-Friction, Lubrication and Wear, 50 Years On, Institution of Mechanical Engineers, London, 1987, pp. 157-172.

[3] S. T. Oktay and N. P. Suh, "Wear Debris Formation and Agglomeration,” ASME Journal of Tribology, Vol. 114, No. 2, 1992, pp. 379-393.

http://dx.doi.org/10.1115/1.2920897

[4] N. Saka, M. J. Liou and N. P. Suh, "The Role of Tribology in Electrical Contact Phenomena,” Wear, Vol. 100, No. 1-3, 1984, pp. 77-105. http://dx.doi.org/10.1016/0043-1648(84)90007-3

[5] N. P. Suh and H. C. Sin, "On the Genesis of Friction and
Its Effect on Wear,” In: H. S. Cheng and L. M. Keer, Eds., Solid Contact and Lubrication, AMD-Vol. 39, ASME, New York, 1980, pp. 167-183.

[6] V. Aronov, A. F. D’Souza, S. Kalpakjian and I. Shareef, "Experimental Investigation of the Effect of System Rigidity on Wear and Friction-Induced Vibrations," ASME Journal of Lubrication Technology, Vol. 105, No. 2, 1983, pp. 206-211. http://dx.doi.org/10.1115/1.3254566

[7] V. Aronov, A. F. D’Souza, S. Kalpakjian and I. Shareef, "Interactions among Friction, Wear, and System Stiffness-Part 1: Effect of Normal Load and System Stiffness,” ASME Journal of Tribology, Vol. 106, No. 1, 1984, pp. 54-58. http://dx.doi.org/10.1115/1.3260867

[8] V. Aronov, A. F. D’Souza, S. Kalpakjian and I. Shareef, "Interactions among Friction, Wear, and System Stiffness_-Part 2: Vibrations Induced by Dry Friction,” ASME Journal of Tribology, Vol. 106, No. 1, 1984, pp. 59-64. http://dx.doi.org/10.1115/1.3260868

[9] V. Aronov, A. F. D’Souza, S. Kalpakjian and I. Shareef, "Interactions among Friction, Wear, and System Stiffness-Part 3: Wear Model,” ASME Journal of Tribology, Vol. 106, No. 1, 1984, pp. 65-69. http://dx.doi.org/10.1115/1.3260869

[10] J. W. Lin and M. D. Bryant, "Reduction in Wear Rate of Carbon Samples Sliding against Wavy Copper Surfaces,” ASME Journal of Tribology, Vol. 118, No. 1, 1996, pp. 116-124. http://dx.doi.org/10.1115/1.2837065

[11] M. A. Chowdhury, M. K. Khalil, D. M. Nuruzzaman and M. L. Rahaman, "The Effect of Sliding Speed and Normal Load on Friction and Wear Property of Aluminum," International Journal of Mechanical \& Mechatronics Engineering IJMME-IJENS, Vol. 11, No. 1, 2011, pp. 4549.

[12] E. P. Becker and K. C. Ludema, "A Qualitative Empirical Model of Cylinder Bore Wear,” Wear, Vol. 225-229, Pt. 1, 1999, pp 387-404. http://dx.doi.org/10.1016/S0043-1648(98)00369-X

[13] M. S. Khan and Z. Hasan, "Effect of Orientation and Applied Load on Abrasive Wear Property of Alumunium Alloy-Al6061," International Journal of Mechanical Engineering \& Technology (IJMET), Vol. 4, No. 4, 2013, pp. 80-87.

[14] M. S. Khan and Z. Hasan, "Abrasive Wear-A Renewal Approach,” International Journal of Engineering Research and Technology, Vol. 6, No. 3, 2013, pp. 60-67. 